\title{
ANNOUNCEMENTS
}

The 157 th meeting of the

\author{
PATHOLOGICAL SOCIETY OF GREAT BRITAIN AND IRELAND \\ will be held at the UNIVERSITY OF NEWCASTLE-UPON-TYNE \\ on July 6 th, 7 th and 8 th, 1988
}

Microbiology Programme (provisional)

Wednesday July 6th a.m. Symposium-Mechanisms of disease production in the gastrointestinal tract.

(Pathophysiological changes; adhesion; toxins; invasion; vaccines)

p.m. Free papers and posters.

Thursday July 7 th a.m. Symposium-Some newer gastrointestinal pathogens.

(Aesomonas spp.; Campylobacter pylori; cryptosporidiosis; viruses; haemolytic uraemic syndrome/haemorrhagic colitis)

p.m. Free papers and posters.

Further information may be obtained from the Meetings Secretary:

Professor E. Mary Cooke, Central Public Health Laboratory,

Division of Hospital Infection, 61 Colindale Avenue, London NW9 5HT.

Tel: 01-200 4400 Ext 4249.

\section{THE WORLD ASSOCIATION OF VETERINARY MICROBIOLOGISTS, IMMUNOLOGISTS AND SPECIALISTS OF INFECTIOUS DISEASES}

\section{First World Congress \\ LYON, France \\ July 25 th-29th, 1988}

The programme includes new developments in animal bacteriology, virology, immunology and infectious diseases of domestic animals.

Also new diagnostic methods, prevention and therapy of these diseases are included. A special session will be reserved for the zoonoses.

The Congress will be of interest not only to specialists working in diagnostic, protection and quality control laboratories but also to veterinarians dealing with infectious diseases of different animal species as well as colleagues specialised in Public Health.

Further information from:

Professor Y. Richard,

École Nationale Vétérinaire de Lyon, route de Sain Bel, Marcy-l'Etoile, 69260 Charbonnières-les-Bains, Lyon, France. 